Original Article

\title{
Cardiopulmonary rehabilitation program impact on prognostic markers in selected patients with resting and exercise-induced ventilatory inefficiency: a clinical trial
}

\author{
Sherin Hassan M. Mehani ${ }^{1 *}$, Heba Ahmed A. Abdeen ${ }^{2)}$ \\ 1) Physical Therapy Department for Internal Medicine, Beni-Suef University: Benisuef Elgadata, Street \\ no.18, Benisuef governorate, Cairo, Egypt \\ 2) Physical Therapy Department for Cardiovascular/Respiratory Disorder and Geriatrics, Faculty of \\ Physical Therapy, Cairo University, Egypt
}

\begin{abstract}
Purpose] Ventilatory limitation is a common problem in patients with chronic heart failure and pulmonary hypertension. Excess ventilation may arise from augmented ventilatory drive, over activity of chemoreceptors and muscle ergoreceptors, or premature onset of lactic acidosis. Exertional dyspnea can cause limitations in the activities of daily living and as a result, reduced quality of life for these patients. The aim of the present study was to evaluate the effect of cardiopulmonary rehabilitation program on ventilatory efficiency for these patients. [Subjects and Methods] Twenty five patients with chronic heart failure and twenty five patients with pulmonary hypertension and only forty of them completed the study. The training program consisted of interval aerobic training program, based on the results of cardiopulmonary exercise testing. Training period was about five months. Outcomes were ventilatory equivalent for $\mathrm{CO} 2,(\mathrm{VE} / \mathrm{VCO} 2$ at anaerobic threshold), $\mathrm{VO} 2$ at anaerobic threshold, $\mathrm{VO} 2$ max and peak work load. Echocardiography parameters were also measured; right ventricular systolic pressure for patients with pulmonary hypertension and ejection fraction for patients with chronic heart failure. [Results] Both groups showed an improvement in ventilation during exercise in favor of patients with pulmonary hypertension. VE/VCO2 decreased by 6.65 in pulmonary hypertension and by 2.9 in chronic heart failure. Right ventricular systolic pressure decreased by $12.05 \mathrm{mmHg}$ in pulmonary hypertension and ejection fraction increased by $17.74 \%$ in chronic heart failure. [Conclusion] Physical therapy cardiopulmonary rehabilitation should be considered in managing patients with ventilatory limitation such as pulmonary hypertension and chronic heart failure.

Key words: Ventilatory limitation, Pulmonary hypertension, Chronic heart failure
\end{abstract}

(This article was submitted Jun. 20, 2017, and was accepted Jul. 11, 2017)

\section{INTRODUCTION}

Pulmonary hypertension is a disease entity which is characterized by structural and functional changes, causing a reduction in the cross sectional area of the small pulmonary arteries ${ }^{1,2}$. This will cause a limited vasodilatory capacity, when cardiac output increases with exercises, with an end result of elevated pulmonary vascular resistance. Pulmonary hypertension can be clinically diagnosed when the mean pulmonary pressure is more than $25 \mathrm{mmHg}^{3,4}$.

The increased pulmonary resistance will overload the right ventricle with ventilation perfusion mismatching and inability to provide oxygenated blood to the peripheral acting muscles ${ }^{5}$. The disease has multiple etiologies such as idiopathic or secondary as a result of autoimmune disease, chronic obstructive pulmonary disease, interstitial pulmonary fibrosis, throm-

*Corresponding author. Sherin Hassn M. Mehani (E-mail: sherinhassin@yahoo.com)

(C2017 The Society of Physical Therapy Science. Published by IPEC Inc.

(c) (1) $\odot$ This is an open-access article distributed under the terms of the Creative Commons Attribution Non-Commercial No DerivaBY NC ND tives (by-nc-nd) License. (CC-BY-NC-ND 4.0: http://creativecommons.org/licenses/by-nc-nd/4.0/) 


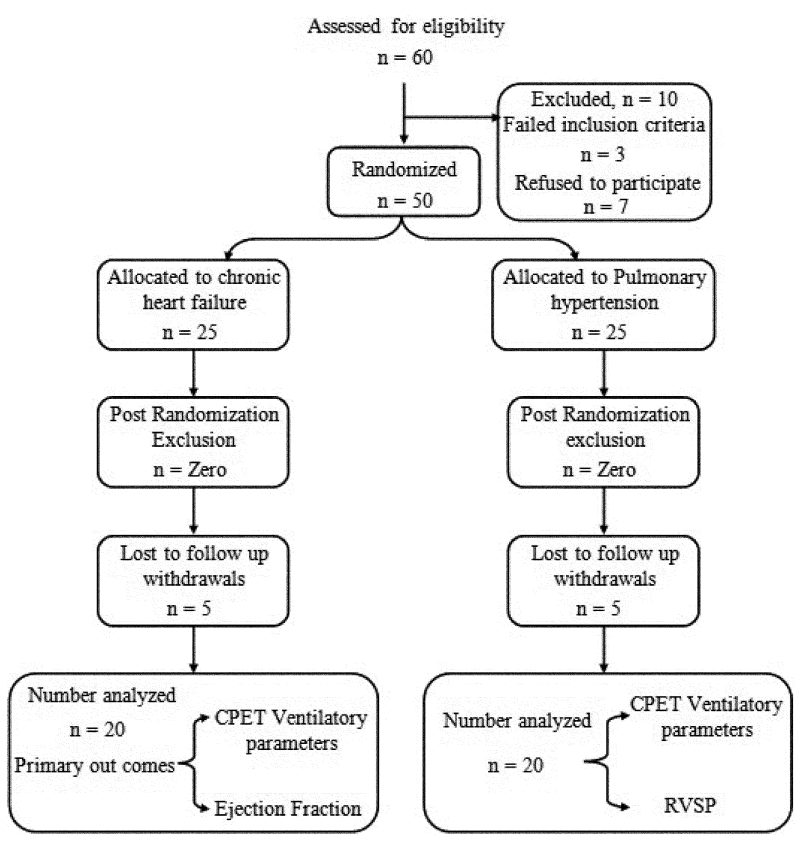

Fig. 1. Flow chart for study procedure

boembolic or connective tissue disease ${ }^{6}$.

Chronic heart failure is a multisystem syndrome characterized by reduction in cardiac output and limited oxygenated blood to the different body organs including the acting muscles ${ }^{7}$. Excess ventilation during exercise is a common sharing problem that cause exercise intolerance in patients with chronic heart failure and pulmonary hypertension ${ }^{8}$.

The precise mechanism for limited ventilation during exercise in these patients is still unknown, it may be the result of augmented ventilatory response to the oversensitive chemoreceptors and muscle ergoreceptors ${ }^{9}$ ), increased physiological dead space as a result of hypoperfusion and an increase in the right ventricle metabolic demand ${ }^{10)}$, or early onset of lactic acidosis $^{11)}$. It is possible that more than one mechanism may share in the ventilatory inefficiency for these patients. Ventilatory inefficiency is defined as excess minute ventilation to eliminate the $\mathrm{CO} 2$ production per minute. Cardiopulmonary exercise testing is a unique, noninvasive gold standard test to evaluate the integrated cardiovascular and pulmonary responses during exercise ${ }^{12,13}$. Ventilatory equivalent for $\mathrm{CO} 2(\mathrm{VE} / \mathrm{VCO} 2)$ is a noninvasive, independent highly prognostic marker and correlated with hemodynamic parameters such as right ventricular systolic pressure and functional capacity parameters such as peak $\mathrm{VO} 2^{14,15)}$

Despite advances in the health care field and pharmaceutics, medications can decrease somewhat the severity of symptoms in these patients, but still exercise - associated with hyperventilation is an incapacitating problem. Exercise training had been shown to improve ventilatory capacity, but still its effect is controversial. So the aim of the present study was to investigate and compare between the effect of tailored aerobic training program in patients with chronic heart failure and patients with pulmonary hypertension who suffered from ventilatory limitation and to explain the underlying mechanism that may be responsible for this improvement. The research questions were:

1. Would cardiopulmonary rehabilitation program improve cardiopulmonary exercise testing and Echocardiography outcomes?

2. Would be and differences between both groups of patients as regards to their response to the program?

\section{SUBJECTS AND METHODS}

Fifty male patients, 25 with symptomatic chronic heart failure and reduced ejection fraction (non-ischemic) and only 20 of them completed the study; they were diagnosed by, Echocardiography and coronary angiography. Patients were recruited from National Heart Institute, outpatient's clinic. Outcome measures were collected before and after five months (Fig. 1). National Heart Institute Ethics Committee approved this study. All participants had written informed consent before data collection began. The study was complying with the ethical standards of Declaration of Helsinki.

For patients with chronic heart failure; all of them had an ejection fraction of less than $40 \%$ and they had sinus rhythm. According to New York heart association (NYHA) classification, they were ranked as II-III class. Their ages were ranged from 50-65 years. Exclusive criteria included; ischemic heart disease, uncontrolled hypertension, severe mitral regurgitation, chronic lung disease and pulmonary hypertension. The study also included 25 male patients with pulmonary hypertension, 
their age ranged between 50-65 years, with a comparable functional capacity classification according to (NYHA) scale. Their right ventricular systolic pressure (which reflects pulmonary vascular resistance) was $>40 \mathrm{mmHg}$ and $<70 \mathrm{mmHg}$. They were excluded if they had severe COPD (as measured pulmonary function testing, FEVI $<35 \%$ from the predicted), severe tricuspid resurge, respiratory failure ( $\mathrm{PaCO} 2>60 \mathrm{mmHg}$ ), uncontrolled systemic hypertension, significant hepatic, renal, thyroid or neuromuscular disorders, peripheral vascular disease, ischemic heart disease, and serious cardiac arrhythmias. All patients were on stable medical treatment and they signed an informed consent before the beginning of study procedure. The study was approved by NHI Ethical committee.

Patients would be withdrawn from the study if they experienced deterioration in their medical condition illustrated by increased medical dose, edema not responding to diuretics, signs of right ventricular failure or hospitalization, for patients with pulmonary hypertension.

Five of the patients in chronic heart failure group, three of them withdrew from the study due to problems in transport and work place, while the other two patients demonstrated exaggerated dyspnea level at exertion in five consecutive training sessions and were referred for cardiologist for further investigation.

Patients in group (A); chronic heart failure group and patients in group (B), pulmonary hypertension group received a supervised, closely monitored cardiac rehabilitation program, consisted of aerobic training in the form of circuit interval training using bicycle ergometry and treadmill for five months. Interval training was defined as repeated exercise bouts of high intensity alternating with exercise bouts of moderate to mild intensity. High intensity was about $80-85 \%$ of heart rate reserve (maximal heart rate - resting heat rate) + resting heart rate. Mild to moderate intensity was about $50-55 \%$ of heart rate reserve -patients also was monitored by Borg scale for perceived exertion, and considered 15-18 points to represent high exercise intensity and $11-13$ points to represent moderate exercise intensity ${ }^{16)}$.

During training sessions, patients were monitored by ECG telemetry; using 3 electrodes (two of them at the 4th space parasternally and the third one at the cardiac apex). For patients with pulmonary hypertension, SPO2 (Saturated hemoglobin) was maintained to be $>92 \%$. Exercise training bouts duration was upgraded according to each patient's response from 2 bouts, each one of them about 8 minutes, for a total time about 20 minutes. Durations of the bouts was upgraded till reaching 4 bouts, for a total duration of forty minutes. Also warming up for 5 minutes and cooling down ( 5 minutes) phases were included in the form of stretching exercises or mild walking on the treadmill.

Outcome measures were M-mode, two dimensional, Pulsed Doppler Echocardiography which performed from supine, left lateral position according to the standards of American Society of Echocardiography ${ }^{17}$.

The examination was done by a single Echocardiography consultant who was blinded to the patient's current ventilatory efficiency before and after the study period. Echocardiography was used to assess right ventricular size and function. Right ventricular systolic pressure (RVSP) was calculated according to Bernoulli equation. In the absence of right ventricular flow obstruction, RVSP was considered to be equal to pulmonary artery systolic pressure. Pulmonary artery systolic pressure was estimated from the maximum or peak tricuspid regurgitation jet velocities according to the Bernoulli equation ${ }^{18)}$.

For patients with chronic heart failure, Echo was also used to evaluate the absence of pulmonary hypertension, as patients with restrictive diastolic dysfunction or pattern were excluded. It was also used to evaluate ejection fraction. All measurements were obtained before and after the study duration.

Submaximal symptom limited Cardiopulmonary exercise testing (CPET) test was done by a specialized physical therapist who was not blinded to the cardiac rehabilitation program and exercise intensity upgrading received by patients in both groups. All patients visited the CPET unit before conducting the test to be familiar with unit and its components. During this visit, brief explanation was given for each patient to avoid premature stopping of the test due to fear from symptoms or lock of motivation.

Pulmonary function testing using spirometry was conducted before CPET, to determine the degree of airway obstruction, using forced expiratory volume in the first second (FEVI) as a percent from the predicted. The test was performed on bicycle ergometry, using Wasserman incremental exercise testing protocol with 3 minutes unloaded bicycle resistance as a warm up, then 5 watts increase per minute, till the patient reach his peak VO2 defined as little increase in oxygen consumption $(150 \mathrm{ml} / 1 \mathrm{~min})$ at 2 consecutive workloads and respiratory exchange ratio not exceeding 1.33 . The test can be also determined if any abnormal signs and symptoms appear such hypotensive response with increasing workload, serious ECG arrhythmias syncopal attacks. Patients with pulmonary hypertension were monitored by pulse oximetry to stop the test, if oxygen saturation dropped below $85 \%$ of the pretest value. Also patients in both groups were monitored by 12 ECG electrodes, and blood pressure was measured before, each 3 minute during testing, and after testing. Peak heart rate was measured at the end of testing to be used for exercise training prescription for rehabilitation program.

Paired t-test was conducted for comparing pre and post training mean values in each group. Mann-Whitney U test was conducted for comparing the percent of improvement between groups. Pearson Correlation Coefficient was conducted to determine the correlation between Echo and indicator. The level of significance for all statistical tests was set at $\mathrm{p}<0.05$. All statistical analysis was conducted through SPSS (statistical package for social sciences, version 19). Sample size calculation was performed at the beginning of the study using G*POWER statistical software (version 3.1.9.2; Franz Faul, Universität Kiel, Germany) (Faul et al., 2009) and revealed that the appropriate sample size for this study was N=40 which gave observed power equal to 0.87 . Calculations were made using $\alpha=0.05, \beta=0.2$ and an effect size of 0.6 . 
Table 1. Comparison of mean age and BMI between pulmonary hypertension and chronic heart failure groups

\begin{tabular}{lccc}
\hline & Pulmonary hypertension & Chronic heart failure & \\
\cline { 2 - 4 } & Mean $\pm \mathrm{SD}$ & Mean $\pm \mathrm{SD}$ & MD \\
\hline Age $($ years $)$ & $49.8 \pm 5.9$ & $51.7 \pm 3.8$ & -1.9 \\
BMI $\left(\mathrm{kg} / \mathrm{m}^{2}\right)$ & $29.2 \pm 5.3$ & $29.6 \pm 3.9$ & -0.41 \\
\hline
\end{tabular}

SD: standard deviation; MD: mean difference; $p$-value, level of significance

Table 2. Comparison of mean resting and maximal heart rate between pulmonary hypertension and chronic heart failure groups

\begin{tabular}{lccc}
\hline & Pulmonary hypertension & Chronic heart failure & \\
\cline { 2 - 4 } Heart rate (beat $/ \mathrm{min})$ & Mean $\pm \mathrm{SD}$ & Mean $\pm \mathrm{SD}$ & MD \\
\hline Resting heart rate & $86.8 \pm 8.5$ & $93.8 \pm 6.9$ & $-7^{*}$ \\
Peak heart rate & $115.6 \pm 11.3$ & $139.9 \pm 12.3$ & $-24.3^{*}$ \\
\hline
\end{tabular}

SD: standard deviation; MD: mean difference; p-value, level of significance; *Significant

Table 3. Comparison between pre and post treatment mean values in pulmonary hypertension and chronic heart failure groups

\begin{tabular}{|c|c|c|c|c|c|}
\hline & & Pre & Post & & \\
\hline & & Mean $\pm \mathrm{SD}$ & Mean \pm SD & $\operatorname{MD}(95 \% \mathrm{CI})$ & $\begin{array}{l}\text { Effect size } \\
\text { (Cohen's d) }\end{array}$ \\
\hline \multirow{5}{*}{$\begin{array}{l}\text { Pulmonary } \\
\text { hypertension }\end{array}$} & $\mathrm{VE} / \mathrm{VCO} 2$ & $39.8 \pm 7.6$ & $33.1 \pm 7.8$ & $6.65(4.5 \text { to } 8.9)^{*}$ & 1.45 \\
\hline & $\mathrm{VO} 2$ at $\mathrm{AT}(\mathrm{ml} / \mathrm{min})$ & $822.1 \pm 228.9$ & $1,088 \pm 358.3$ & $-265.9(-349.24 \text { to }-182.55)^{*}$ & -1.49 \\
\hline & Peak VO2 (\%) & $46.7 \pm 8.4$ & $56.0 \pm 7.2$ & $-9.35(-10.86 \text { to }-7.83)^{*}$ & -2.89 \\
\hline & Peak work load (watts) & $42.9 \pm 21.6$ & $63.7 \pm 24.4$ & $-20.8(-27.22 \text { to }-14.37)^{*}$ & -1.51 \\
\hline & RVSP (mmHg) & $56.9 \pm 11.3$ & $44.9 \pm 10.0$ & $12.05(10.73 \text { to } 13.36)^{*}$ & 4.27 \\
\hline \multirow{5}{*}{$\begin{array}{l}\text { Chronic heart } \\
\text { failure }\end{array}$} & $\mathrm{VE} / \mathrm{VCO} 2$ & $30.9 \pm 2.2$ & $28.0 \pm 2.0$ & $2.9(2.27 \text { to } 3.52)^{*}$ & 2.15 \\
\hline & $\mathrm{VO} 2$ at $\mathrm{AT}(\mathrm{ml} / \mathrm{min})$ & $1,049.2 \pm 259.7$ & $1,451.5 \pm 287.9$ & $-402.3(-575.75 \text { to } 228.84)^{*}$ & -1.08 \\
\hline & Peak VO2 (\%) & $59.9 \pm 8.7$ & $79.3 \pm 11.1$ & $-19.45(-24.56 \text { to }-14.33)^{*}$ & -1.77 \\
\hline & Peak work load (watts) & $103.7 \pm 21.3$ & $127.8 \pm 22.7$ & $-24.1(-29.05 \text { to }-19.14)^{*}$ & -2.27 \\
\hline & EJFR (\%) & $33.0 \pm 4.6$ & $50.7 \pm 8.2$ & $-17.74(-21.78 \text { to }-13.68)^{*}$ & -2.04 \\
\hline
\end{tabular}

SD: standard deviation; MD: mean difference, p-value, level of significance; *Significant; VE/VCO2: ventilatory equivalent for CO2 at anaerobic threshold; VO2 at AT: Oxygen consumption at anaerobic threshold; VO2max: maximal oxygen consumption as a percentage from the predicted, RVSP: right ventricular systolic pressure; EJFR: ejection fraction

\section{RESULTS}

Table 1, showed the mean \pm SD age and BMI of pulmonary hypertension and chronic heart failure groups. There was no significant difference between both groups in the mean age and BMI $(\mathrm{p}<0.05)$.

Table 2, showed the mean \pm SD resting and maximal heart rate of pulmonary hypertension and chronic heart failure groups. There was a significant difference in resting and maximal heart rate between pulmonary hypertension group and chronic heart failure group ( $\mathrm{p}>0.01)$.

The mean values of Vo2 at AT, VO2 max, and peak work load were significantly increased post training compared with pre-training ( $>0.0001)$, while there was a significant decrease in VE/VCO2 and RVSP post training compared to pre-training $(\mathrm{p}>0.0001)$ in pulmonary hypertension group (Table 3 ).

Similar to results in pulmonary hypertension group the mean values of Vo2 at AT, VO2 max, peak work load, and Ejection fraction of chronic heart failure group were significantly increased post training compared to pre-training ( $>00.0001)$, while there was a significant decrease in VE/VCO2 post training compared to pre-training ( $>0.0001)$ in Chronic heart failure group (Table 3).

There was a significant increase in percent of change of VE/VCO2 and peak work load of pulmonary hypertension group compared with chronic heart failure group ( $>0.01)$, while there was a significant decrease in percent of change of VO2 max of pulmonary hypertension group compared with chronic heart failure group $(p>0.01)$. There was no significant difference in 
Table 4. Comparison of percent of change between pulmonary hypertension and chronic heart failure groups

\begin{tabular}{lcc}
\hline & Pulmonary hypertension & Chronic heart failure \\
\hline Median percent of change & Median (IQR) & Median (IQR) \\
VE/VCO2 & $18.97(10.4)$ & $10.62(6.4)^{*}$ \\
VO2 at AT (ml/ min) & $-33.11(25.32)$ & $-21.57(87.52)$ \\
Peak VO2 (\%) & $-20.39(18.69)$ & $-30.44(19.24)^{*}$ \\
Peak work load (watts) & $-54.47(57.46)$ & $-22.33(23.42)^{*}$ \\
\hline
\end{tabular}

IQR: interquartile range; p-value, level of significance; *Significant

Table 5. Correlation between Echocardiography parameters and ventilatory parameters

\begin{tabular}{llr}
\hline Echocardiography parameters & Ventilatory parameters & r value \\
\hline \multirow{2}{*}{ RVSP $(\mathrm{mmHg})$} & $\mathrm{VE} / \mathrm{VCO} 2$ & $0.32^{*}$ \\
& $\mathrm{VO} 2$ at AT $(\mathrm{ml} / \mathrm{min})$ & $-0.57^{*}$ \\
EJFR $(\%)$ & $\mathrm{VE} / \mathrm{VCO} 2$ & $-0.48^{*}$ \\
& $\mathrm{VO} 2$ at $\mathrm{AT}(\mathrm{ml} / \mathrm{min})$ & $0.56^{*}$ \\
\hline
\end{tabular}

$r$ value: correlation coefficient value; $p$ value: probability value, *Significant

percent of change of VO2 at AT between groups $(\mathrm{p}<0.05)$ (Table 4).

There was a positive moderate significant correlation between RVSP and VE/VCO2 ( $\mathrm{r}=0.32, \mathrm{p}=0.04)$, while there was a negative moderate significant correlation between RVSP and Vo2 at AT ( $(\mathrm{r}=-0.57, \mathrm{p}=0.0001)$ (Table 5).

There was a negative moderate significant correlation between EJFR and VE/VCO2 $(\mathrm{r}=-0.48, \mathrm{p}=0.002)$, while there was a positive moderate significant correlation between EJFR and Vo2 at AT ( $\mathrm{r}=0.56, \mathrm{p}=0.0001)$ (Table 5).

\section{DISCUSSION}

Patients with pulmonary hypertension had a diminished perfusion as a result of increased pulmonary artery pressure, and as a consequence ventilation-perfusion mismatching with a resultant increase in physiological dead space. To compensate for the increased dead space, the VE/VCO2 rate at anaerobic threshold should be increased ${ }^{19}$. Another mechanism responsible for the increase in $\mathrm{VE} / \mathrm{VCO} 2$ is the reduction in red blood cells transit time, with a consequent arterial desaturation, that would be compensated by an increase in ventilatory equivalent for $\mathrm{CO}^{20}$.

The reduction in peak $\mathrm{VO} 2$ and $\mathrm{VO} 2$ at anaerobic threshold in the patients may be as a result of reduction in cardiac output which arises from displaced interventricular septum towards the left side as a result of increased right sided pressure ${ }^{15}$.

Ventilatory equivalent for $\mathrm{CO} 2$ (VE/VCO2) obtained from submaximal symptom limited cardiopulmonary exercise testing (CPX) may be prognostic marker ${ }^{21)}$, and in a previous study done by Groepenhoff et al. ${ }^{22}$, was positively, correlated with the right atrial pressure and mean pulmonary artery pressure, on the other hand, measuring $\mathrm{VO} 2$ at anaerobic threshold is considered as a submaximal parameter obtained from CPX and its improvement after a certain intervention, is a reflection for improvement in activities of daily living ${ }^{23}$. Using CPX for systolic heart failure patients indicated that VE/VCO2 and peak VO2 were the most studied prognostic variables ${ }^{12}, 24$.

Excess ventilation with exercise in patients with systolic heart failure, measured as VE/VCO2, is a strong independent predictor of outcomes and risk identification as recommended by the European society of cardiology ${ }^{25}$.

Previous studies had been conducted to compare between ventilatory limitations in pulmonary hypertension and chronic heart failure patients and these studies concluded that disturbed ventilation perfusion ratio plays a major role in association with increased ergoreceptors and chemoreceptors activation, which in turn causes sympathetic nervous system over activity. On the other hand in patients with pulmonary hypertension, sympathetic nervous system activation rather than increased dead space ventilation plays a major role. These studies also concluded that patients with pulmonary hypertension were presented with higher ventilatory equivalents than patients with chronic heart failure as revealed by the present study ${ }^{8,26)}$.

The present study showed that VE/VCO2 at anaerobic threshold was 39.75 in pulmonary hypertension, while it was 30.91 in heart failure associated with a more reduction in VO2 at anaerobic threshold in pulmonary hypertension patient $(822.1 \mathrm{ml} / \mathrm{min}$ versus $1049.15 \mathrm{ml} / \mathrm{min}$ in heart failure patients), before beginning of the cardiac rehabilitation on program.

Deboeck et al. ${ }^{5}$, revealed that anaerobic threshold occurred at a higher percentage of peak VO2 than in normal subjects as a result of reduction in the peak VO2 in both pulmonary hypertension and chronic heart failure patients. This may be attributed to the higher resting oxygen consumption, as noted in the present study, and to the slower rising of oxygen consumption 
above the anaerobic threshold ${ }^{27}$.

From the results of the present study, patients with chronic heart failure achieved a higher maximal heart rate (139.9 b/min) as compared with pulmonary hypertension patients $(93.75 \mathrm{~b} / \mathrm{min})$, with a significant difference in between both groups, on the other hand, there was a significant difference in the percentage of change in the peak work load in comparing both groups in favor of the pulmonary hypertension group. The previous finding may be explained by down regulation of right ventricular $\beta$-mechanoreceptors of the myocardium, reflecting more chronotropic incompetence in pulmonary hypertension patients, as supported by Bristow et al. ${ }^{28)}$, considering that both groups were on the same beta-blocker dose therapy.

The results of the present study revealed that there was a significant increase in VO2 at anaerobic threshold, VO2 max as a percentage from the predicted and peak workload in both groups, while there was a significant reduction in ventilatory equivalent for $\mathrm{CO} 2$ [VE/VCO2] and right ventricular systolic pressure in the pulmonary hypertension group. On the other hand, there was a significant reduction in $\mathrm{VE} / \mathrm{VCO} 2$ along with significant increase in the left ventricular ejection fraction in chronic heart failure patients. The results of the present study go ahead with Weinstein et al. ${ }^{4}$, who concluded that aerobic training with an intensity about $70-80 \%$ of heart rate reserve obtained from treadmill test had increased cardiorespiratory fitness as indicated by an increase in the peak work load about 25 watts (with a similar increase was observed in the present study) in the pulmonary hypertension group, but the previous study included only a small sample of females.

Ganderton et al. ${ }^{2)}$, investigated the effect of lower limb endurance training with an exercise intensity about $60-70 \%$ of HR max (based on maximal predicted heart rate) along with functional strength training for the lower limb and endurance training for the upper limb in a group of patients with pulmonary hypertensions for about 12 weeks outpatient supervised training followed by home-based program. The main outcome of the study was to determine the safety of outpatient rehabilitation program for patients with pulmonary hypertension and they determined a withdrawal criteria from rehabilitation program and one of these criteria was deterioration in $\mathrm{VE} / \mathrm{VCO} 2$, reflecting gas exchange worsening and as shown in the present study, there was a reduction in ventilatory equivalent for $\mathrm{CO} 2$ Concomitant with successful and safe rehabilitation program.

A number of ingoing trials studying the effect of exercise based rehabilitation were conducted by De Mann et al. ${ }^{29)}$, Martinez Quintana et al. ${ }^{30)}$, and shoemaker et al. ${ }^{31)}$, but these trials were non-randomized controlled trials or case reports.

The results of the present study had showed a significant positive moderate correlation $(\mathrm{R}=0.32)$ between right ventricular systolic pressure (RVSP) and VE/VCO2 along with significant negative moderate correlation $(\mathrm{R}=-0.5)$ between $\mathrm{RVSP}$ and $\mathrm{VO} 2$ at AT.

The previous finding may indicate the importance of right ventricular systolic pressure in improving ventilation during exercise as right ventricle could contribute to sensation of dyspnea through its mechanoreceptors which transmits information to central nervous system through afferent sympathetic pathway. So reducing right ventricular pressure can decrease sympathetic stimulation, and improve ventilation with effort ${ }^{32)}$. The increased oxygen consumption at anaerobic threshold (VO2 at AT) may be another mechanism contributing to improved ventilation with exercise as it reflects a reduction in the muscle $\mathrm{PH}$ and so reduction in lactate production along with reduced stimulation of intra and extra cellular chemoreceptors and ergoreceptors ${ }^{33)}$. The improvement observed in functional capacity in patients with pulmonary hypertension may also be attributed to improvement in muscle morphology (increased type I fibers) and mitochondrial enzyme density ${ }^{34)}$.

The positive correlation between RVSP and VE/VCO2 was ensured by Fowler et al. ${ }^{35)}$, Panagiotous et al. ${ }^{36)}$, Grunig et al., ${ }^{37)}$ concluded that exercise training can induce central adaptations (reduction in pulmonary artery pressure) and cardiac function (improvement of peak oxygen consumption) in patients with pulmonary hypertension.

Coats $^{38)}$ concluded that patients with CHF had abnormal ventilatory control at rest and with exercise as indicated by increased $\mathrm{VE} / \mathrm{VCO} 2$ and exercise rehabilitation for 8 weeks, using intensity about $70-80 \%$ of maximal heart rate caused a reduction in the slope of $\mathrm{VE} / \mathrm{VCO} 2$, indicating an improved ventilatory efficiency. Exercise training as shown in the present study induced central adaptations as represented by the increase in left ventricular ejection fraction (LVEF) which coincided with the results reported by Haykowsky et al. ${ }^{39}$, who showed the training - reverse remodeling in patients with CHF as a result of improved myocardial contractility, enhanced ventricular capacitance and improved vascular reserve. Exercise training could induce modification in the muscle aerobic capacity, capillary density, and mitochondrial volume.

Using low exercise intensity prescription (50-60\%) could induce the previous changes along with an increase in the peak VO2. However high intensity is necessary to increase the dominance of type I muscle fibers and decrease type $\mathrm{II}^{40)}$. The increase in peak VO2 and VO2 at AT observed in the present study in the patients with CHF may be attributed to using interval aerobic training with high and low intensity. Using of high intensity aerobic training was also supported by Papathanassiou et al. ${ }^{16)}$ and Patwala et $\mathrm{al}^{41)}$.

The results of the present study showed a significant negative moderate correlation between ejection fraction and VE/VCO2 and this may indicate that improved cardiac pumping along with peripheral muscular adaptations could delay muscle fatigue with effort and so less lactate production along with better lactate clearance, less chemoreceptors and ergo receptors activity and as a consequence better ventilation with exercise ${ }^{7}$. On the other hand the improved cardiac output pumped by the heart as shown in the present study after rehabilitation program could improve ventilation perfusion mismatching and so decreasing the physiological dead space with a concomitant decrease in the ventilatory equivalent to get out $\mathrm{CO} 2$.

By comparing the percent of changes in VE/VCO2 in the patients with pulmonary hypertension and the other group of patients with CHF, there was a significant difference between both groups in favor of pulmonary hypertension, despite these patients were more ventilatory limited before the beginning of rehabilitation program (VE/VCO2=39.75 versus 30.91 in 
patients with CHF).

Data from this study confirm that patients with pulmonary hypertension and chronic heart failure had ventilatory limitation at rest and during exercise with a critical implication for breathlessness and decreased the activities of daily living. Exercise training is not a cure for them, but effective and safe cardiopulmonary rehabilitation program can improve their ventilatory efficiency. Exercise should be seen as a vital strategy to reduce the progression of, or even partly reserve the maladaptations that occur through the course of both syndromes. The study was limited to only investigating the effect of lower limb individualized interval aerobic training and did not include inspiratory muscle training, so future studies are needed to evaluate the effect of combined aerobic and respiratory training. Longitudinal studies are also needed to evaluate the effect of rehabilitation program on morbidity and mortality outcomes.

\section{REFERENCES}

1) Barreto SS: Assessment of exercise capacity in pulmonary hypertension. J Bras Pneumol, 2009, 35: 401-403. [Medline] [CrossRef]

2) Ganderton L, Jenkins S, Gain K, et al.: Short term effects of exercise training on exercise capacity and quality of life in patients with pulmonary arterial hypertension: protocol for a randomised controlled trial. BMC Pulm Med, 2011, 11: 25. [Medline] [CrossRef]

3) Benza RL, Miller DP, Gomberg-Maitland M, et al.: Predicting survival in pulmonary arterial hypertension; insights from the registry to evaluate early and long term pulmonary arterial 2004, hypertension disease management. Circulation, 2010, 122: 164-172. [Medline] [CrossRef]

4) Weinstein AA, Chin LM, Keyser RE, et al.: Effect of aerobic exercise training on fatigue and physical activity in patients with pulmonary arterial hypertension. Respir Med, 2013, 107: 778-784. [Medline] [CrossRef]

5) Deboeck G, Niset G, Lamotte M, et al.: Exercise testing in pulmonary arterial hypertension and in chronic heart failure. Eur Respir J, 2004 , 23: 747-751. [Medline] [CrossRef]

6) Hunt SA, Baker DW, Chin MH, et al.: ACC / AHA guidelines for the evaluation and management of chronic heart failure in the adults: executive summary. A report of the American College of Cardiology/American Heart Association Task Force on practice guidelines. J Am Coll Cardiol, 2001, 38: 101-113. [CrossRef]

7) Asrar U1 Haq M, Goh CY, Levinger I, et al.: Clinical utility of exercise training in heart failure with reduced and preserved ejection fraction. Clin Med Insights Cardiol, 2015, 9: 1-9. [Medline] [CrossRef]

8) Naeije R: Breathing more with weaker respiratory muscles in pulmonary arterial hypertension. Eur Respir J, 2005, 25: 6-8. [Medline] [CrossRef]

9) Witte KK, Clark AL: Why does chronic heart failure cause breathlessness and fatigue? Prog Cardiovasc Dis, 2007, 49: 366-384. [Medline] [CrossRef]

10) Ukkonen H, Burwash IG, Dafoe W, et al.: Is ventilatory efficiency (VE/VCO(2) slope) associated with right ventricular oxidative metabolism in patients with congestive heart failure? Eur J Heart Fail, 2008, 10: 1117-1122. [Medline] [CrossRef]

11) Sue DY: Excess ventilation during exercise and prognosis in chronic heart failure. Am J Respir Crit Care Med, 2011, 183: 1302-1310. [Medline] [CrossRef]

12) Guazzi M, Adams V, Conraads V, et al. EACPR AHA: EACPR/AHA Joint Scientific Statement. Clinical recommendations for cardiopulmonary exercise testing data assessment in specific patient populations. Eur Heart J, 2012, 33: 2917-2927. [Medline] [CrossRef]

13) Balady G J, Arena R: Clinician's guide to cardiopulmonary exercise testing in adults; a scientific statement from the American Heart Association, 2010, 122: 191-225.

14) Kim CH, Jae SY, Johnson BD: Pulmonary hypertension and cardiopulmonary exercise in heart failure. Pulse Basel, 2014, 1: 143-151. [Medline] [CrossRef]

15) Arena R, Lavie CJ, Milani RV, et al.: Cardiopulmonary exercise testing in patients with pulmonary arterial hypertension: an evidence based review. Heart and Lung Transplant, 2010, 29: 159-173.

16) Papathanasiou JV, Ilieva EM, Nikolov FP: Exercise training modes in rehabilitation of patients with chronic heart failure. Folia Med (Plovdiv), 2012 , 54: $22-28$. [Medline]

17) Cheitlin MD, Armstrong WF, Aurigemma GP, et al. ACC AHA ASE: ACC/AHA/ASE 2003 Guideline Update for the Clinical Application of Echocardiography: summary article. A report of the American College of Cardiology/American Heart Association Task Force on Practice Guidelines (ACC/AHA/ASE Committee to Update the 1997 Guidelines for the Clinical Application of Echocardiography). J Am Soc Echocardiogr, 2003, 16: 1091-1110. [Medline]

18) Grünig E, Weissmann S, Ehlken N, et al.: Stress Doppler echocardiography in relatives of patients with idiopathic and familial pulmonary arterial hypertension: results of a multicenter European analysis of pulmonary artery pressure response to exercise and hypoxia. Circulation, 2009, 119: 1747-1757. [Medline] [CrossRef]

19) Wasserman K, Hansen JE, Sue DY, et al.: pathophysiology of disorders limiting exercise. In: Weinberg A (ed.), Principles of exercise testing and interpretation, 4th ed. Philadelphia: Lippincott Williams and Wilkins, 2005, pp111 - 132.

20) Ferrazza AM, Martolini D, Valli G, et al.: Cardiopulmonary exercise testing in the functional and prognostic evaluation of patients with pulmonary diseases. Respiration, 2009, 77: 3-17. [Medline] [CrossRef]

21) Arena R, Myers J, Guazzi M: The clinical and research applications of aerobic capacity and ventilatory efficiency in heart failure: an evidence-based review. Heart Fail Rev, 2008, 13: 245-269. [Medline] [CrossRef]

22) Groepenhoff H, Vonk-Noordegraaf A, Boonstra A, et al.: Exercise testing to estimate survival in pulmonary hypertension. Med Sci Sports Exerc, 2008, 40: 1725-1732. [Medline] [CrossRef]

23) Arena R, Myers J, Williams MA, et al. American Heart Association Committee on Exercise, Rehabilitation, and Prevention of the Council on Clinical Cardiology American Heart Association Council on Cardiovascular Nursing: Assessment of functional capacity in clinical and research settings: Scientific statement from the American Heart Association committee on exercise, rehabilitation, and prevention of the council on clinical cardiology and the council on cardiovascular nursing. Circulation, 2007, 116: 329-343. [Medline] [CrossRef]

24) Khatri V, Neal JE, Burger CD, et al.: Prognostication in pulmonary arterial hypertension with submaximal exercise testing. Diseases, 2015, 3: 15-23. [CrossRef] 
25) Palange P, Ward SA, Carlsen KH, et al. ERS Task Force: Recommendations on the use of exercise testing in clinical practice. Eur Respir J, 2007, 29: 185-209. [Medline] [CrossRef]

26) Ponikowski P, Chua TP, Anker SD, et al.: Peripheral chemoreceptor hypersensitivity: an ominous sign in patients with chronic heart failure. Circulation, 2001, 104: 544-549. [Medline] [CrossRef]

27) Riley MS, Pórszász J, Engelen MP, et al.: Gas exchange responses to continuous incremental cycle ergometry exercise in primary pulmonary hypertension in humans. Eur J Appl Physiol, 2000, 83: 63-70. [Medline] [CrossRef]

28) Bristow MR, Minobe W, Rasmussen R, et al.: $\beta$-adrenergic neuroeffector abnormalities in the failing human heart are produced by local rather than systemic mechanisms. J Clin Invest, 1992, 89: 803-815. [Medline] [CrossRef]

29) de Man FS, Handoko ML, Groepenhoff H, et al.: Effects of exercise training in patients with idiopathic pulmonary arterial hypertension. Eur Respir J, 2009, 34: 669-675. [Medline] [CrossRef]

30) Shoemaker MJ, Wilt JL, Dasgupta R, et al.: Exercise training in patients with pulmonary arterial hypertension: a case report. Cardiopulm Phys Ther J, 2009, 20: 12-18. [Medline]

31) Martínez-Quintana E, Miranda-Calderín G, Ugarte-Lopetegui A, et al.: Rehabilitation program in adult congenital heart disease patients with pulmonary hypertension. Congenit Heart Dis, 2010, 5: 44-50. [Medline] [CrossRef]

32) Ciarka A, Vachièry JL, Houssière A, et al.: Atrial septostomy decreases sympathetic overactivity in pulmonary arterial hypertension. Chest, 2007, 131: 1831-1837. [Medline] [CrossRef]

33) Clark AL: Origin of symptoms in chronic heart failure. Heart, 2006, 92: 12-16. [Medline] [CrossRef]

34) Mainguy V, Maltais F, Saey D, et al.: Peripheral muscle dysfunction in idiopathic pulmonary arterial hypertension. Thorax, 2010, 65: 113-117. [Medline] [CrossRef]

35) Fowler RM, Gain KR, Gabbay E: Exercise intolerance in pulmonary arterial hypertension. Pulm Med, 2012, 2012: 359204. [Medline] [CrossRef]

36) Panagiotou M, Peacock AJ, Johnson MK: Respiratory and limb muscle dysfunction in pulmonary arterial hypertension: a role for exercise training? Pulm Circ, 2015, 5: 424-434. [Medline] [CrossRef]

37) Grünig E, Lichtblau M, Ehlken N, et al.: Safety and efficacy of exercise training in various forms of pulmonary hypertension. Eur Respir J, 2012 , 40: 84-92. [Medline] [CrossRef]

38) Coats AJ: Clinical utility of exercise training in chronic systolic heart failure. Nat Rev Cardiol, 2011, 8: 380-392. [Medline] [CrossRef]

39) Haykowsky MJ, Liang Y, Pechter D, et al.: A meta-analysis of the effect of exercise training on left ventricular remodeling in heart failure patients: the benefit depends on the type of training performed. J Am Coll Cardiol, 2007, 49: 2329-2336. [Medline] [CrossRef]

40) Tabet JY, Meurin P, Driss AB, et al.: Benefits of exercise training in chronic heart failure. Arch Cardiovasc Dis, 2009, 102: 721-730. [Medline] [CrossRef]

41) Patwala AY, Woods PR, Sharp L, et al.: Maximizing patient benefit from cardiac resynchronization therapy with the addition of structured exercise training: a randomized controlled study. J Am Coll Cardiol, 2009, 53: 2332-2339. [Medline] [CrossRef] 